\title{
Tratamento de efluentes de abatedouro de frangos por meio de reator UASB seguido de filtro anaeróbio
}

[Treatment of waste water poultry slaughter house through UASB reactor followed by anaerobic filter]

\author{
L.S. Rodrigues ${ }^{1}$, B.C. Lopes ${ }^{2}$, C.A. Lima $^{2}$, M.C. Ribeiro ${ }^{3}$, R.P. Santos ${ }^{4}$, I.J. Silva \\ ${ }^{1}$ Universidade Federal de Minas Gerais - UFMG - Belo Horizonte, MG \\ ${ }^{2}$ Aluna de pós-graduação - UFMG - Belo Horizonte, MG \\ ${ }^{3}$ Aluno de graduação - CEFET - Belo Horizonte, MG \\ ${ }^{4}$ Aluna de graduação - UFMG - Belo Horizonte, MG \\ ${ }^{5}$ Universidade Federal de Minas Gerais - UFMG - Belo Horizonte, MG
}

\begin{abstract}
RESUMO
O Brasil é um dos maiores produtores de aves do mundo e se destaca na exportação de carne de frango, que tem papel relevante na economia do país. Como resultado do crescimento da indústria de processamento do frango, há também um significativo aumento na geração de efluentes. Uma alternativa interessante para o tratamento desses resíduos são os reatores anaeróbios. Este trabalho teve como objetivo avaliar o desempenho do sistema reator UASB-Filtro anaeróbio no tratamento de efluentes de abate de frangos. O estudo foi desenvolvido em um abatedouro avícola, situado na região metropolitana de Belo Horizonte, Minas Gerais. O sistema de tratamento foi composto por peneira estática, caixa de gordura, reator UASB e filtro anaeróbio. A vazão média diária de efluentes do abatedouro foi de $30 \mathrm{~m}^{3} /$ dia. A carga orgânica aplicada no reator UASB foi de $0,71 \mathrm{~kg} \mathrm{DQO} / \mathrm{m}^{3} . \mathrm{d}$. O monitoramento do sistema foi realizado por meio de análises físico-químicas do afluente e dos efluentes da caixa de gordura, reator UASB e filtro anaeróbio. Os parâmetros avaliados foram: temperatura, $\mathrm{pH}$, demanda química de oxigênio (DQO), demanda bioquímica de oxigênio (DBO), sólidos suspensos totais (SST), e sólidos suspensos voláteis (SSV). Os valores efluentes médios encontrados para DBO, DQO e SST foram 106, 290 e $56 \mathrm{mg} / \mathrm{L}$, respectivamente. A eficiência de remoção do sistema para DBO variou de 83 a $99 \%$, e para DQO de 50 a $98 \%$. A eficiência de remoção média de SST e SSV foi de $92 \%$. Conclui-se que o sistema reator UASB seguido de filtro anaeróbio apresentou alto desempenho na remoção de sólidos e carga orgânica. Dessa forma, esses reatores tornam-se uma alternativa viável para o tratamento de águas residuárias de frigoríficos, já que oferecem bons resultados de remoção de poluentes.
\end{abstract}

Palavras-chave: digestão anaeróbia, impacto ambiental, agroindústria, remoção de sólidos, carga orgânica

\begin{abstract}
Brazil is one of the largest poultry producers in the world and stands out in exportation of chicken meat, which plays an important role in the economy. As a result of the growth of the poultry processing industry, there is also a significant increase in the generation of wastewater. An interesting alternative for the treatment of such wastes is anaerobic. This study aimed to evaluate the performance of the system UASB reactor-anaerobic filter on wastewater treatment of slaughtering chickens. The study was conducted in a poultry slaughterhouse located in the metropolitan region of Belo Horizonte, Minas Gerais. The treatment system was composed of static sieve, grease trap, UASB reactor and anaerobic filter. The daily average flow of effluent from the abattoir was $30 \mathrm{~m}^{3} /$ day. The organic load applied to the UASB reactor was $0.71 \mathrm{~kg} C O D / \mathrm{m}^{3} . d$. The monitoring system was performed by means of physicochemical analysis of the influent and effluent of fat, UASB reactor and anaerobic filter. The parameters evaluated were: temperature, $p H$, chemical oxygen demand (COD), biochemical oxygen demand (BOD), total suspended solids (SS) and volatile suspended solids (VSS). The mean values for effluent BOD, COD
\end{abstract}

Recebido em 2 de julho de 2014

Aceito em 17 de agosto de 2015

E-mail: 1santosrodrigues@gmail.com 
and SS were 106, 290 and 56mg/L, respectively. The removal efficiency of BOD to the system ranged 8399\% for COD and 50-98\%. The average removal efficiency of SS and SSV were $92 \%$. We conclude that the system UASB reactor followed by anaerobic filter showed high performance in removing solids and organic load. Thus, these reactors become a viable alternative for treating wastewater slaughterhouses, offering good results in removing pollutants.

Keywords: anaerobic digestion, environmental impact, agribusiness, removal of solids, organic load

\section{INTRODUÇÃO}

A indústria de processamento de frangos gera grande potencial poluidor, pois suas águas residuárias são ricas em matéria orgânica, sólidos, gordura e nutrientes, o que torna necessário o estudo de alternativas para seu tratamento (Chavez et al., 2005).

Atualmente, os processos de tratamento anaeróbio têm sido frequentemente apontados para tratamento de águas residuárias com elevadas concentrações de material orgânico biodegradável, como as de abatedouro avícola. Esses processos são interessantes devido às suas características peculiares, como baixa produção de sólidos, baixo consumo de energia, baixo custo de implantação e operação, tolerância a elevadas cargas orgânicas e baixos tempo de detenção hidráulica (TDH). Nesse cenário, o reator anaeróbio de manta de lodo (ou upflow anaerobic sludge blanket - UASB) tem obtido destaque.

De maneira geral, os processos anaeróbios de alta taxa podem ser operados com cargas orgânicas bem superiores às dos reatores anaeróbios convencionais. Porém, para que o desempenho máximo do sistema seja alcançado, muitas vezes esses processos demandam um controle mais rigoroso na partida e no melhor controle operacional.

Tendo em vista o impacto causado pelos efluentes da indústria avícola e visando estudar meios de evitar a poluição ambiental e a contaminação das águas, o presente trabalho tem como objetivo avaliar o desempenho e a aplicabilidade do reator UASB como tratamento de águas residuárias de abate de frangos.

\section{MATERIAL E MÉTODOS}

O trabalho foi desenvolvido em uma estação de tratamento de efluentes em escala real, presente em um abatedouro avícola situado na região metropolitana de Belo Horizonte (Minas Gerais). Essa estação foi projetada para um abate diário de 3000 aves/dia, sendo sua vazão diária média de aproximadamente $90 \mathrm{~m}^{3} / \mathrm{dia}$. Além disso, seu sistema de tratamento é constituído de tratamento preliminar, primário e secundário.

O tratamento preliminar objetiva a remoção de sólidos grosseiros, sendo realizado por meio de uma peneira estática de aço inox, com orifícios de $1,0 \mathrm{~mm}$ de diâmetro. Por sua vez, o tratamento primário, que visa remover sólidos sedimentáveis, é constituído por uma caixa de gordura gravimétrica de $12 \mathrm{~m}^{3}$ e um tanque de equalização e acidificação (TAE) de $24 \mathrm{~m}^{3}$.

Posteriormente, tem-se o tratamento secundário, que é constituído de um reator anaeróbio de mata de lodo (reator UASB) de $108 \mathrm{~m}^{3}$. Neste, por meio de um processo biológico, compostos solúveis orgânicos presentes no efluente são convertidos em produtos intermediários finais, como metano e gás carbônico. A carga orgânica aplicada no reator durante o estudo foi de $0,50 \mathrm{~kg}$ $\mathrm{DQO} / \mathrm{m}^{3}$ dia.

Como pós-tratamento, a estação possui um filtro anaeróbio (FA) de $117,6 \mathrm{~m}^{3}$, utilizado para garantir a eficiência do processo. Ele consiste de um tanque preenchido com material de enchimento (pedras britadas $\mathrm{n}^{\circ} 4$ ), que é utilizado como meio suporte para o desenvolvimento de biofilmes de microrganismos presentes no reator. A Fig.1 mostra o fluxograma geral da estação: 


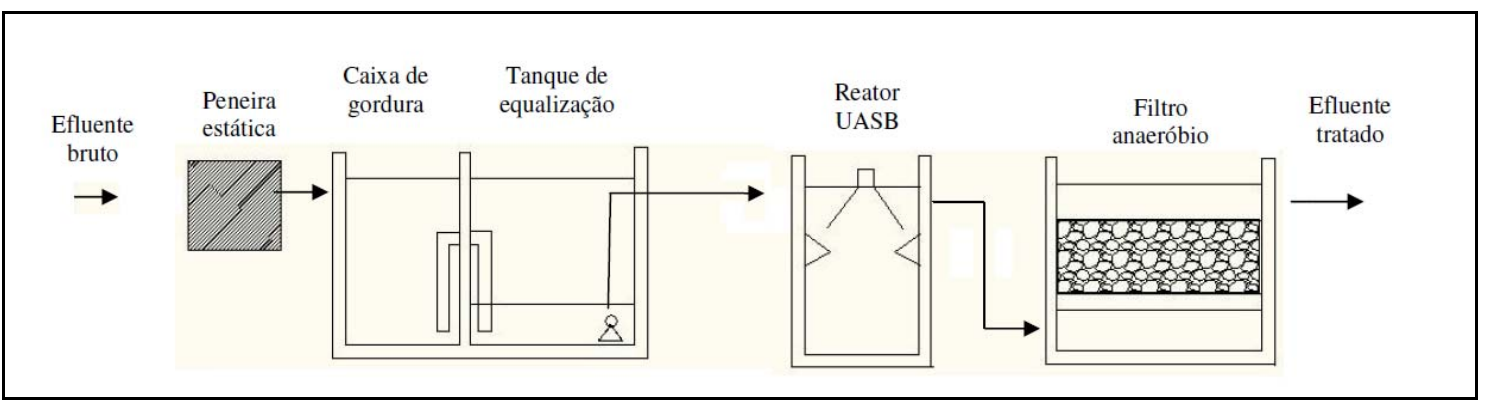

Figura 1. Fluxograma geral da estação de tratamento de efluentes (ETE).

A partida desse sistema foi realizada utilizando lodo de uma lagoa anaeróbia de suinocultura como inóculo. O lodo foi deixado em repouso por um período entre 24 e 48 horas, para possibilitar a sua adaptação gradual à temperatura ambiente. Com o término do repouso, foi iniciada a alimentação do sistema, a qual foi realizada utilizando-se $15 \mathrm{~m}^{3}$ do efluente do abatedouro, que representa $50 \%$ da vazão diária. Essa alimentação parcial foi realizada durante os cinco primeiros dias, sendo alterada depois para escala real.

O monitoramento foi realizado por meio de análises físico-químicas do afluente e dos efluentes da peneira estática, da caixa de gordura, do reator UASB e do FA. Como parâmetros, foram avaliados temperatura, $\mathrm{pH}$, demanda química de oxigênio (DQO), demanda bioquímica de oxigênio (DBO), sólidos suspensos totais (SST) e sólidos suspensos voláteis (SSV), os quais foram realizados conforme metodologia descrita no Standard Methods for Examination of Water and Wastewater (APHA,2012).

\section{RESULTADOS E DISCUSSÃO}

$\mathrm{Na}$ Tab.1, são mostrados os valores médios e o desvio-padrão dos parâmetros físico-químicos avaliados durante o período de monitoramento do afluente e efluentes da caixa de gordura, do reator UASB e do filtro anaeróbio.

A temperatura média do ar durante o período experimental no reator UASB e no FA foi inferior ao do afluente, porém permaneceu com valores superiores a $20^{\circ} \mathrm{C}$, demonstrando que tanto o reator UASB como o FA operaram na faixa mesofílica de temperatura $\left(20\right.$ a $\left.45^{\circ} \mathrm{C}\right)$, embora inferior à faixa ótima de crescimento dos microrganismos $\left(30 \mathrm{a} 35^{\circ} \mathrm{C}\right)$.

Souza et al. (2005), avaliaram a partida de biodigestores de bancada, alimentados com dejetos de suíno, com $6.000 \mathrm{mg} / \mathrm{L}$ de sólidos totais, submetidos a três temperaturas diferentes $\left(25,35\right.$ e $\left.40^{\circ} \mathrm{C}\right)$. Os resultados demonstraram que as temperaturas de 35 e $40^{\circ} \mathrm{C}$ favoreceram a partida dos biodigestores, pois resultaram em maior produção acumulada de biogás e em menor tempo, quando comparadas a de $25^{\circ} \mathrm{C}$.

Tabela 1. Valores médios e desvios-padrão da carga orgânica volumétrica (COV), tempo de detenção hidráulico (TDH) e concentração dos parâmetros físico-químicos das águas residuárias do abate de frangos afluentes e efluentes à caixa de gordura, ao reator UASB e ao filtro anaeróbio durante o período experimental

\begin{tabular}{lcccc}
\hline \multicolumn{1}{c}{ Parâmetro } & Afluente ETE & \multicolumn{3}{c}{ Efluente } \\
\cline { 3 - 5 } & & Caixa de gordura & Reator UASB & FA \\
\hline COV $\left(\mathrm{kg} / \mathrm{m}^{3} . \mathrm{d}\right)$ & - & - & $0,71 \pm 0,45$ & $0,23 \pm 0,12$ \\
TDH $(\mathrm{d})$ & - & - & $3,00 \pm 0,36$ & $3,05 \pm 0,36$ \\
Temperatura $\left({ }^{\circ} \mathrm{C}\right)$ & $24 \pm 1,31$ & $22 \pm 2,00$ & $23 \pm 1,85$ & $23 \pm 2,15$ \\
pH & $6,94 \pm 0,53$ & $6,45 \pm 0,16$ & $6,81 \pm 0,19$ & $7,20 \pm 0,21$ \\
DBO $(\mathrm{mg} / \mathrm{L})$ & $1903 \pm 672$ & $904 \pm 332$ & $314 \pm 151$ & $106 \pm 116$ \\
DQO $(\mathrm{mg} / \mathrm{L})$ & $3626 \pm 1554$ & $1680 \pm 1174$ & $782 \pm 359$ & $290 \pm 194$ \\
SST $(\mathrm{mg} / \mathrm{L})$ & $841 \pm 349$ & $420 \pm 240$ & $310 \pm 310$ & $56 \pm 40$ \\
SSV $(\mathrm{mg} / \mathrm{L})$ & $562 \pm 297$ & $320 \pm 289$ & $153 \pm 70$ & $39 \pm 33$ \\
\hline
\end{tabular}


Fernandes e Oliveira (2006), ao trabalharem com água residuária de suinocultura em sistema anaeróbio de dois estágios (reator anaeróbio compartimentado seguido de reator UASB), com TDH de 56 e $28 \mathrm{~h}$ e COV de 5,05 e $7,81 \mathrm{~kg}$ $\mathrm{DQO} / \mathrm{m}^{3} . \mathrm{d}$, respectivamente, para os ensaios um e dois, alcançaram eficiência de remoção de DQO e SST de 87 e $86 \%$, respectivamente, para temperatura média de $18,2^{\circ} \mathrm{C}$ (ensaio 1). Mesmo com o diminuição do TDH e o aumento da COV do ensaio 2 em relação ao 1 , as remoções aumentaram para 95 e 96\%, respectivamente, para DQO e SST, devido, segundo os autores, ao aumento da temperatura média para $21,6^{\circ} \mathrm{C}$.

Pode-se observar uma tendência de aumento dos valores de $\mathrm{pH}$ (Fig.2) no decorrer do tratamento, contudo os valores médios para os efluentes do reator UASB e do FA ficaram na faixa de neutralidade. Tal fato se deve à estabilidade na faixa de $\mathrm{pH}$ entre 6,5 e 8,5 , pois, nessa faixa, o $\mathrm{pH}$ é controlado pela capacidade tampão do sistema, relacionada ao equilíbrio dos carbonatos, representado principalmente pela alcalinidade devido ao bicarbonato, a qual é determinante para a estabilidade da digestão anaeróbia de resíduos orgânicos (Iamamoto, 2002).

Os valores médios encontrados para DBO e DQO foram semelhantes ao encontrados por Torkian e Hashemian (2003), Nardi et al. (2005), Leifeld et al. (2009), e Rajakumar et al. (2011) e são devido à grande quantidade de resíduos orgânicos presentes nesses tipos de efluentes, como sangue, vísceras e gorduras.

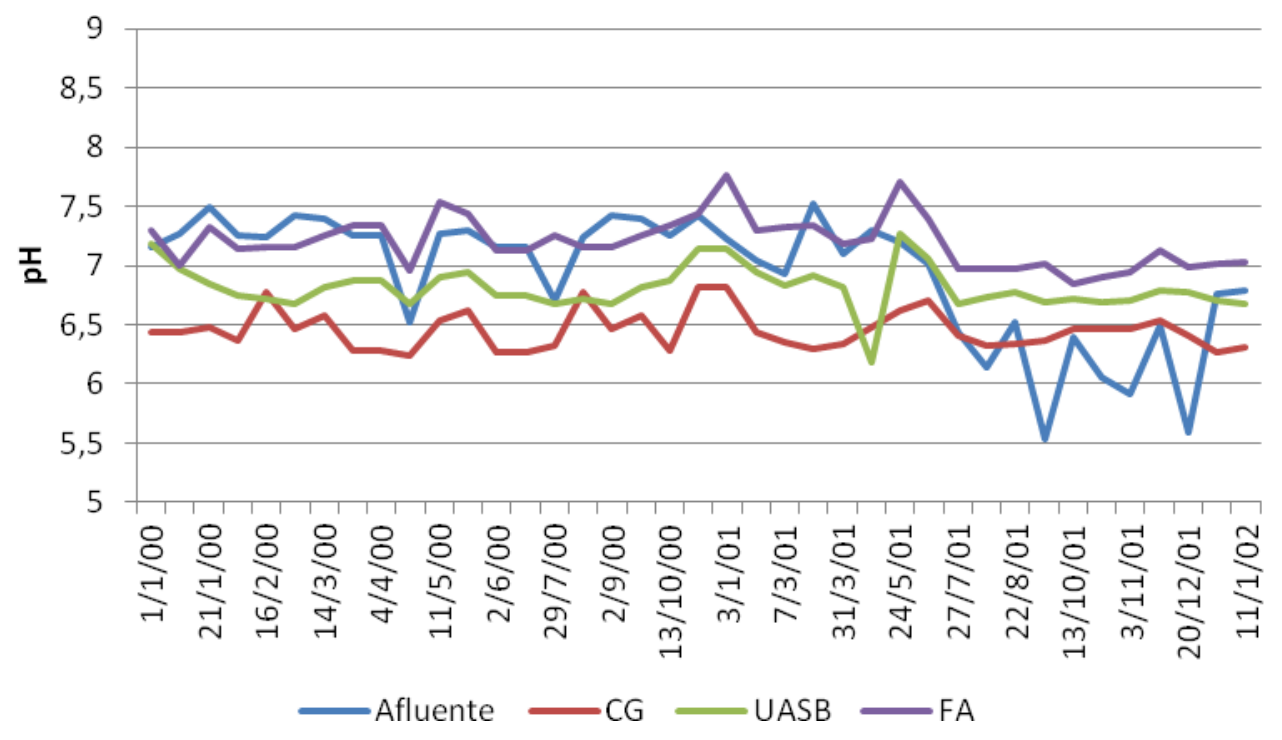

Figura 2. Variações do $\mathrm{pH}$ nas águas residuárias do abate de frango afluentes e efluentes à caixa de gordura (CG), ao reator UASB (UASB) e ao filtro anaeróbio (FA) durante o período experimental.

Nas Fig. 3 e 4, são mostradas as séries temporais de DBO e DQO, nas quais se nota a grande variação nos valores afluentes, durante o período experimental, com redução dessa variabilidade ao passarem pelas unidades de tratamento.

Os efluentes de DBO e DQO do reator UASB e do FA apresentaram valores mais altos nos primeiros 75 dias, que correspondem ao período de partida do sistema.

No reator UASB, com COV aplicada de $0,71 \mathrm{~kg}$ de $\mathrm{DQO} / \mathrm{m}^{3}$.d, e TDH médio de 3,00 dias, os valores médios de eficiência de remoção de DQO e DBO foram de 55,8 e 63,3\% (Tab. 2), respectivamente. 


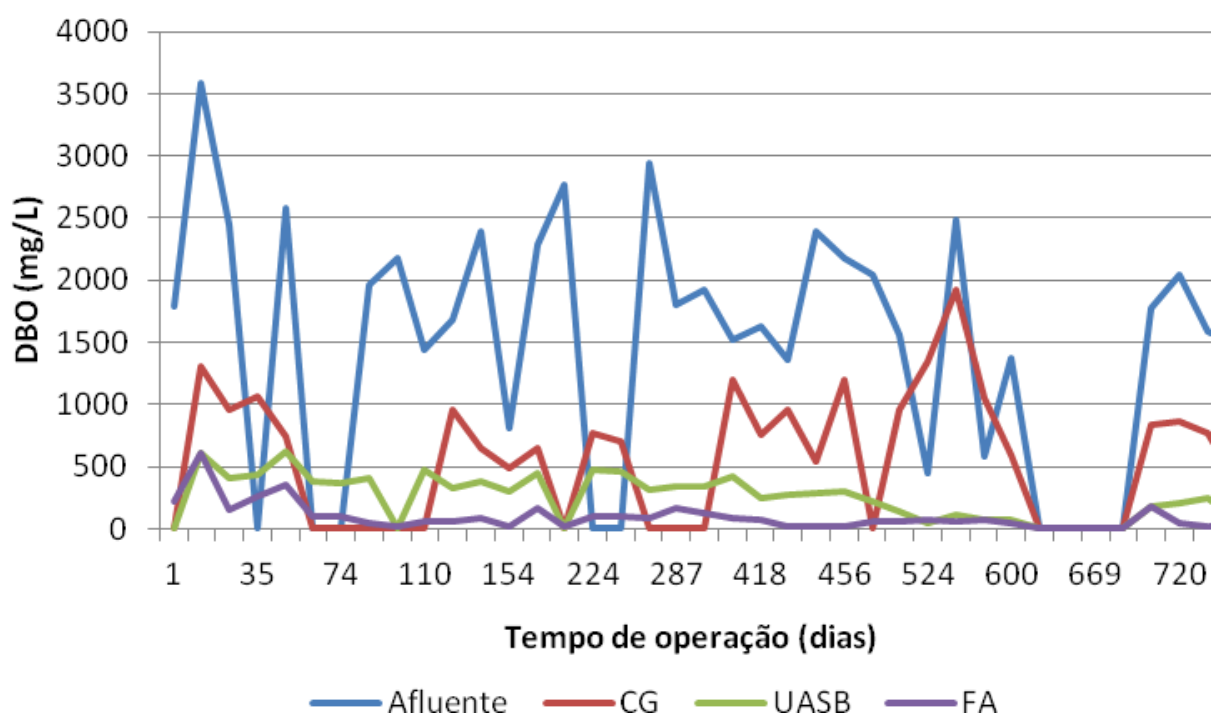

Figura 3. Variações da DBO nas águas residuárias do abate de frango afluentes e efluentes à caixa de gordura (CG), ao reator UASB (UASB) e ao filtro anaeróbio (FA) durante o período experimental.

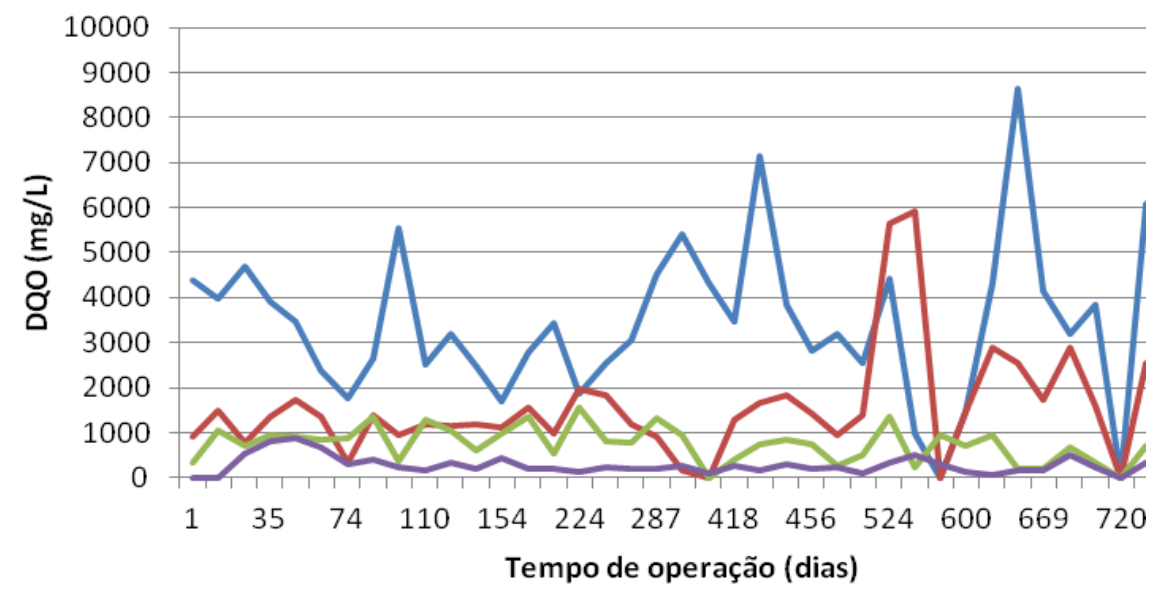

- Afluente $\longrightarrow$ CG UASB $\longrightarrow$ FA

Figura 4. Variações da DQO nas águas residuárias do abate de frango afluentes e efluentes à caixa de gordura (CG), ao reator UASB (UASB) e ao filtro anaeróbio (FA) durante o período experimental.

Os valores médios de eficiência de remoção de DBO e DQO no FA foram de 69,2 e 60,8\%, respectivamente, sendo maiores do que no reator UASB, com COV aplicado de $0,23 \mathrm{~kg}$ de $\mathrm{DQO} / \mathrm{m}^{3} . \mathrm{d}$, e TDH médio de 3,05 . A eficiência global do sistema foi superior a $90 \%$ para DBO e
DQO, cumprindo com o que estabelece a legislação do estado de Minas Gerais, DN Copam/CERH 01/2008, quanto à eficiência de remoção da ETE. 


\section{Rodrigues et al.}

Tabela 2. Valores médios de eficiência de remoção (\%) de DBO, DQO, SST e SSV das unidades que compõem a ETE no tratamento de águas residuárias do abate de frango

\begin{tabular}{lcccc}
\multicolumn{1}{c}{ Parâmetro } & Caixa de gordura & Reator UASB & Filtro anaeróbio & Global \\
\hline DBO & $52,8 \pm 17,1$ & $63,3 \pm 22,1$ & $69,2 \pm 21,2$ & $94,8 \pm 4,7$ \\
DQO & $57,3 \pm 20,9$ & $55,8 \pm 22,2$ & $60,8 \pm 24,6$ & $89,8 \pm 9,9$ \\
SST & $59,1 \pm 16,5$ & $50,4 \pm 20,7$ & $72,9 \pm 20,9$ & $91,6 \pm 10,5$ \\
SSV & $61,8 \pm 15,2$ & $36,2 \pm 20,3$ & $72,65 \pm 17,5$ & $91,5 \pm 10,8$ \\
\hline
\end{tabular}

Massé e Masse (2000) estudaram quatro reatores anaeróbios compartimentados que receberam efluentes de frigorífico com DQO variando de 6908 a $11500 \mathrm{mg} / \mathrm{L}$, obtendo redução de 90 a 96\% para uma carga orgânica aplicada nos reatores na faixa de 2,07 a $4,93 \mathrm{~kg}$ de $\mathrm{DQO} / \mathrm{m}^{3} . \mathrm{d}$ e tempo de detenção hidráulico de dois dias.

Torkiane Hashemian (2003) operaram um reator UASB de $1 \mathrm{~m}^{3}$ com carga orgânica aplicada variando de 13 a $39 \mathrm{~kg}$ de DQO $/ \mathrm{m}^{3}$.d e tempo de detenção hidráulico de duas a sete horas, obtendo remoções de DQO de 75 a 90\% para afluentes de 3000 a $4500 \mathrm{mg} / \mathrm{L}$.

Por sua vez, ao se analisarem os resultados de sólidos suspensos totais (SST) e sólidos suspensos voláteis (SSV) nas Fig. 5 e 6, constatase que houve uma redução desses parâmetros durante o período experimental, com altas eficiências de remoção no filtro anaeróbio, o que proporcionou eficiência do sistema acima de $90 \%$, produzindo um efluente com valores abaixo do padrão de lançamento de $100 \mathrm{mg} / \mathrm{L}$ estabelecido pela DN Copam/CERH 01/2008.

Duda e Oliveira (2011), que utilizaram FA para suinocultura, encontraram valores médios de SST efluente de $600 \mathrm{mg} / \mathrm{L}$.

Leifeld et al. (2009) estudaram o emprego de filtros anaeróbios no tratamento de efluentes de abatedouro com tempos de detenção hidráulico variando de 48 a 120 horas e obtiveram eficiências de remoção de DQO, ST e STV variando de 48,4 a $87,0 \%, 39,08$ a $78,56 \%$ e 56,55 a $86,91 \%$, respectivamente.
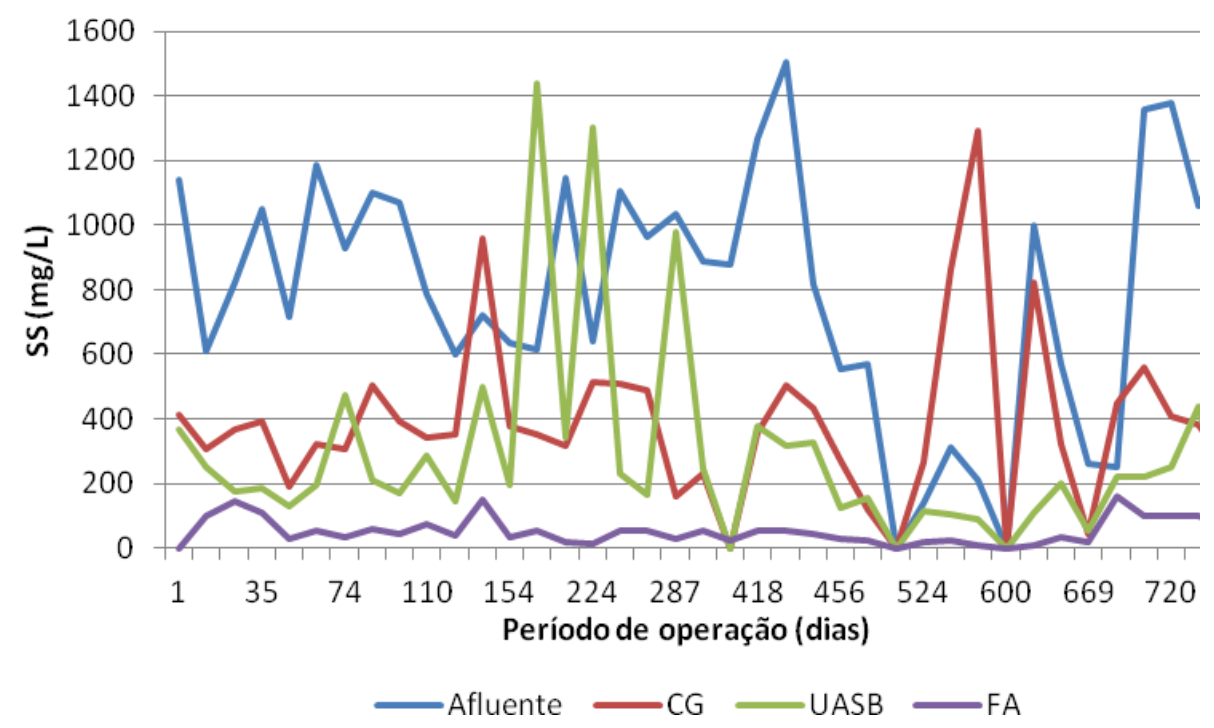

Figura 5. Variações de SST nas águas residuárias do abate de frango afluentes e efluentes à caixa de gordura (CG), ao reator UASB (UASB) e ao filtro anaeróbio (FA) durante o período experimental. 


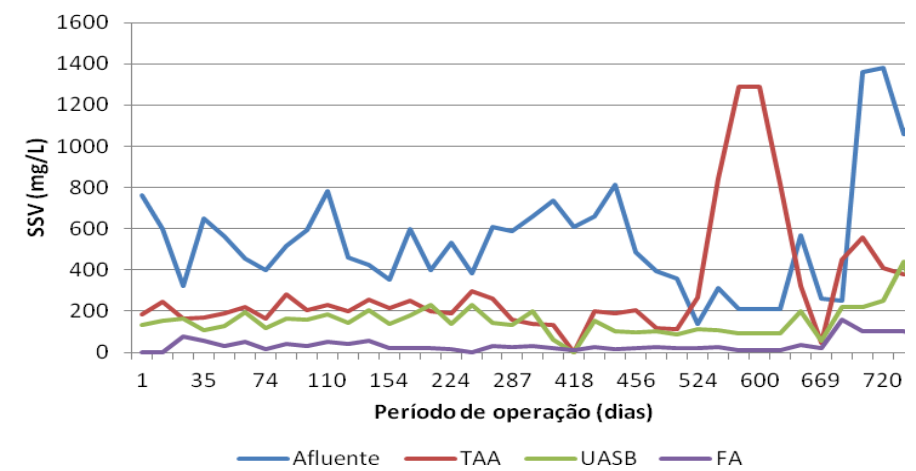

Figura 6. Variações de SSV nas águas residuárias do abate de frango afluentes e efluentes à caixa de gordura (CG), ao reator UASB (UASB) e ao filtro anaeróbio (FA) durante o período experimental.

\section{CONCLUSÕES}

O sistema de reatores anaeróbios em dois estágios apresentou alto desempenho na remoção de sólidos e carga orgânica, podendo ser uma alternativa viável para o tratamento de águas residuárias de frigoríficos, já que oferece bons resultados de remoção e baixo custo de implantação.

\section{REFERÊNCIAS}

CHAVEZ, C.P; CASTILLO, R.L; DENDOOVEN, L.; ESCAMILLA-SILVA, E.M. Poultry slaughter wastewater treatment with an up-flow anaerobic sludge blanket (UASB) reactor. Bioresource Technol., v.96, p.1730-1736, 2005.

DUDA, R.M; OLIVEIRA, R. Tratamento de águas residuárias de suinocultura em reator UASB e filtro anaeróbio seguidos de filtro biológico percolador. Eng. Sanit. Ambient., v.16, p.91-100, 2011.

FERNANDES, G.F.R.; OLIVEIRA, R.A. Desempenho de processo anaeróbio em dois estágios (reator compartimentado seguido de reator UASB) para tratamento de águas residuárias de suinocultura. Eng. Agric., v.26, p.243-256, 2006.

IAMAMOTO, C.Y.; OLIVEIRA, R.A.; LUCAS JUNIOR, J. Alcalinidade como medida de monitoramento do desempenho de reatores anaeróbios de fluxo ascendente com manta de lodo (UASB), tratando águas residuárias de suinocultura. Eng. Agríc., v.22, p.118-126, 2002.

LEIFELD, V.; RIVAS, L.M.C.G.; BARANA, A.C. Comparação entre filtros biológicos anaeróbios para o tratamento de efluente de abatedouro com diferentes sistemas de alimentação. Rev. Eng. Tecnol., v.1, p.96102, 2009.
MASSÉ, D.I.; MASSE, L. Treatment of slaughterhouse wastewater in anaerobic sequencing batch reactors. Canadian Agricultural Engineering, v.42, p.131-137, 2000.

MINAS GERAIS. Deliberação Normativa COPAM/CERH $n^{\circ}$ 01, de 05 de maio de 2008. Dispõe sobre a classificação dos corpos de água e diretrizes ambientais para o seu enquadramento, bem como estabelece as condições e padrões de lançamento de efluentes, e dá outras providências. (Diário do Executivo - "Minas Gerais"-16/09/2010)

NARDI, I.R.. LIMA, A.R.; AMORIM, A.K.B.; DEL NERY, V. Análise de séries temporais na operação de sistema de tratamento de águas residuárias de abatedouro de frangos. Eng. Sanit. Ambient., v.10, p.339-346, 2005.

RAJAKUMAR, R.; MEENAMBAL, T.; BANU, J.R.; YEON, I.T. Treatment of poultry slaughterhouse wastewater in upflow anaerobic filter under low upflow velocity. Int. Environ Sci Technol., v.8, p.149158, 2011.

SOUZA, C.F.; LUCAS JUNIOR, J.; FERREIRA, W.P.M. Biodigestão anaeróbia de dejetos de suínos sob efeito de três temperaturas e dois níveis de agitação do substrato: considerações sobre a partida. Engenharia Agrícola, v.25, p.530-539, 2005.

STANDARD methods for the examination of water and wastewater. 21.ed. Washington: American Public Health Association, 2012. 1569 p.

TORKIAN, A.; HASHEMIAN, A.E.S.J. The effect of organic loading rate on the performance of UASB reactor treating slaughterhouse effluent. Resour. Conserv. Recy., v.40, p.1-11, 2003. 